\title{
Role of Omega-3 Fatty Acid in Childbearing Age Women with Vitamin D Deficiency in Sana'a City
}

\author{
Doa'a Anwar Ibrahim ${ }^{1, *}$, Rawya Shehab ${ }^{2}$, Molok Saleh², Shyma'a Ali², Kawther Al-Hamati², Abdulsalam Halboup ${ }^{1}$ \\ 'Department of Clinical Pharmacy and Pharmacy Practice, Sana'a, YEMEN. \\ 2Department of Pharmacology, Faculty of Pharmacy, University of Science and Technology, Sana'a, YEMEN.
}

\begin{abstract}
Background: The optimal intake of nutrients is a new approach to deriving nutrient requirements. Omega-3 is one of these nutrients that has a crucial role in body health. It can modulate inflammation, hyperlipidemia, platelet aggregation, and hypertension. Objectives: This study was designed as a pilot study to evaluate the efficacy and safety of omega-3 fatty acid in improving the level of Vitamin D and calcium among Childbearing age women that suffer from Vitamin D deficiency. Methods: 10 childbearing women with Vitamin D deficiency. They were selected randomly. The participants were allowed to take one capsule $(1000 \mathrm{mg})$ of omega 3 FA twice daily for 12 weeks. Results: Omega-3 FA showed significant beneficial effects on Vitamin $D$, calcium levels in Vitamin $D$ deficit childbearing women. Additionally, it showed cardioprotective effects as it reduced bad lipids like cholesterol, LDL-c, risk factor and had worthwhile effects on blood coagulation. Conclusion: The outcomes of the present
\end{abstract}

study suggest that omega-3 FA if taken regularly by childbearing women may improve their maternal outcomes and save their own lives and their babies. It may have a golden standard role in bone health through strength and activation of Vitamin D thus facilitates calcium absorption and increase bone mineral density. Additionally, it has cardioprotective and immune modulation effects.

Key words: Omega-3 FA, Childbearing women, Vitamin D deficiency, Sana' City, Yemen

\section{Correspondence}

Prof. Doa'a Anwar Ibrahim

Professor of Clinical Pharmacology and Therapeutics, Sana'a, YEMEN

Phone no: +967-733308292

Email:dr_d_anwar@hotmail.com

DOI: 10.5530/ijpi.2021.1.22

\section{INTRODUCTION}

The prevalence of Vitamin D deficiency increase among women of different ages in the last decades. ${ }^{1}$ This deficiency may be referred to reduce optimal nutrition, which is one of the most important determinants of healthier different aging. These maintain the mental and physical functions and improve the quality of life. ${ }^{2,3}$ However, many studies focused on the benefits role of omega 3 fatty acids on the cardiovascular system, inflammation as well as immune-modulating actions $^{4-6}$ Omega-3 fatty acids have two important physiological functions in the human body. First, they are present as lipid bilayer phospholipid of the cell membrane that facilitates communication and cell membrane functions. Second, they consider as precursors of eicosanoids, which are bioactive lipid mediators that act as paracrine and autocrine throughout the body. ${ }^{7.8}$

In humans alpha-linolic acid considers the essential n-3 FA. ${ }^{8}$ In most people, it can be converted to longer chain n-3 FAs, eicosapentaenoic acid (EPA) and docosahexaenoic acid (DHA). This conversion appears to be small in extent, especially with Western diets that high with $\mathrm{n}-6$ Fas. ${ }^{910}$ EPA and DHA are found in the diet especially from marine sources that are incorporated into blood and tissues. Vitamin D has a golden role in perinatal health as it prevents many disorders like rickets and preserves normal bone metabolism and musculoskeletal health. ${ }^{11}$ However, Vitamin D deficiency in pregnant women may result in myopathy as a result of poor skeletal mineralization in utero life and this contributed to the higher delivery complications like caesarian births influenced musculoskeletal growth, with poor skeletal mineralization in utero and myopathy developing earlier than any biochemical signs of bone disease $\mathrm{e}^{12,13}$ and contributed to higher rates of caesarian births. ${ }^{14}$ Some studies showed that Vitamin D and omega-3 FA supplements have beneficial effects in the treatment of different musculoskeletal conditions..$^{15}$

Of the several potential mechanisms whereby n-3 FAs may affect bone and they potentiate the effect of Vitamin D which has a crucial role in the bone metabolic bone process. Two of the best defined involve decreasing pro-inflammatory cytokines critical to the regulation of bone turnover and modulating calcium balance. Cytokines are key regulators of the osteoprotegerin/receptor activator of NFKB ligand (OPG/RANKL) ratio in the bone. RANKL is expressed in osteoblasts and activates its receptor, RANK, which is expressed on osteoclasts, thus promoting osteoclast formation and activation, as well as suppressing apoptosis of osteoclasts. Osteoprotegerin (OPG) is a secretory glycoprotein expressed by osteoblasts that block RANKL (Receptor Activator of Nuclear Factor kappa-B Ligand) from activating RANK (Receptor Activator of NF- $\mathrm{kB}$ ). The ratio of OPG/RANKL is critical in the pathogenesis of the resorptive bone disease, with a higher ratio indicating less bone resorption. ${ }^{16-18}$ All these effects favoring bone formation over bone resorption.

Yemen, as a developing country, there is a noticeable poor health situation like poverty, sedentary life due to khat chewing, smoking, unhealthy foods intake and refrain to intake the food that rich with calcium and Vitamin D like fish, milk, honey, cereals, and dates due to poor economic life and political instability. All these results in the suffering of the population particularly childbearing women from Vitamin D deficiency thus result in adverse pregnancy outcomes. Many works of literature found that omega 3 fatty acids as nutrients or supplements might have the potential of preventing and reducing co-morbidities. As a long-chain fatty acid found in different food sources especially in fish and fish oil that is also formulated as a commercial product, it has health benefits, particularly 
in bone health. It improves bone mineral density that reduces the hip and supine fractures. ${ }^{18}$ This study aims to assess the level of awareness of childbearing women towards vitamin D deficiency and the factors associated with this level of awareness to discover the gap in the first part of this study. The second observational part tried to constrict this gap by studying the role of omega-3 FA on Vitamin D and calcium deficiencies and other parameters.

\section{MATERIALS AND METHODS}

\section{Materials}

Omega-3 FA (Natural fish oil) was supplied from Vitex Pharmaceutical Australian Made and Owned product.

\section{Methods}

This study was designed to evaluate the efficacy and safety of omega 3 FA on the Vitamin D and calcium levels in childbearing women with Vitamin D deficiency through baseline Vitamin D level. Participants that in childbearing age are included and in the study and the postmenopause, women with chronic diseases or taking medications that interfere with vitamin D level were excluded from the study. Ethical permission [No. EAC/UST183] was obtained from the Ethics Committee at the University of Science and Technology-Sana'a. The study was conducted according to the Declaration of Helsinki guidelines. It was declared to all volunteers that participated in this study that all information was kept confidential and used only for research purposes.

Ten participants with a deficiency of Vitamin D serum 25OHD concentration $<12 \mathrm{ng} / \mathrm{ml}$ were selected randomly. They accepted to enroll in this study after an explanation that omega 3 FA has no effect on their healthy state and they are free to withdraw from this study any time. They allowed taking one capsule $(1000 \mathrm{mg})$ of omega 3 FA twice daily for 12 weeks. Different parameters were measured at baseline and after commencing the trial, including calcium, and vitamin D. Liver function enzymes (LFTs), complete blood count (CBC), lipid profile, blood pressure, and BMI all these additional parameters were measured to assess the efficacy of Omega-3 FA intake as supplementary vitamin either on Vitamin D or body health improvement.

\section{Data analysis}

The collected data obtained was firstly verified and coded before entry and analyzed by SPSS (SPSS Inc. Chicago, IL, USA) version 21 software. $t$-test was used to analyze the biochemical part. The confidence interval $95 \%$ and a $p<0.05$ were considered significant.

\section{RESULTS}

The interventional study showed that consumption of one capsule / twice daily omega-3 FA as a supplement for 12weeks resulted in significant improvement of Vitamin D from baseline11.7 \pm 2.1 to $16.3 \pm 1.04$ after treatment with $p$-value 0.005 and calcium level from baseline $2.2 \pm 0.05$ to $2.7 \pm 0.02$ after treatment with $p$-value 0.0001 . Additionally, omega 3 FA showed significant improvement in lipid profile as it reduced cholesterol levels from baseline $177.2 \pm 7.25$ to 155 . $8 \pm 4.85$ after treatment with p-value 0.04 . LDL-c was reduced from baseline124.7 \pm 8.21 to $98.3 \pm 5.20$ after treatment with p-value 0.042 , also TG, HDL and risk factor all showed improvement but insignificantly as shown in Figure 1-4.

Regarding the safety of omega 3 fatty acid supplements, it produced an insignificant change in fasting blood sugar (FBS) and liver function tests (LFTs). However, it produced a significant effect $(p<0.05)$ in prothrombin time (PT) from baseline 11. $2 \pm 0.1$ to $11.9 \pm 0.2$ after treatment with $p$-value $=0.008$ and international normalized ratio (INR) from baseline
$1.23 \pm 0.01$ to $1.1 \pm 0.03$ after treatment with $p$-value $=0.014$ as shown in Table 1.

Table 2 showed insignificant change in blood pressure and body mass index (BMI) in participants who took omega-3 FA for 12 weeks. Additionally, Table 3 showed an insignificant reduction in $\mathrm{CBC}$ except for $\mathrm{Hb}$.

\section{DISCUSSION}

According to the World Bank, Yemen is the poorest country in the Middle East as well as the North Africa region. Nowadays, Yemen is suffering from the worst crisis in the world, particularly on the humanitarian level. Fighting and unstable political situation has affected the economy of the country, infrastructure that already destroyed, which threatens starvation due to lack of food security. ${ }^{19}$ Childbearing age women are

Table 1: Effect of omega-3 fatty acid on (mean \pm SE) FBS, LFTS, PT and INR in the participants for 12 weeks.

\begin{tabular}{cccc}
\hline Parameters & \multicolumn{2}{c}{ Mean \pm SE } \\
\cline { 2 - 4 } & Baseline & After & p-value \\
\hline FBS (mg/dl) & $4.72 \pm 0.12$ & $4.84 \pm 0.07$ & 0.13 \\
LFTs & & & \\
SGOT (U/L) & $16.7 \pm 0.93$ & $15.7 \pm 1.02$ & 0.3 \\
SGPT (U/L) & $10.1 \pm 0.90$ & $9.44 \pm 0.96$ & 0.4 \\
T. bilirubin(U/L) & $12.6 \pm 2.10$ & $11.9 \pm 1.80$ & 0.8 \\
D. bilirubin(U/L) & $3.67 \pm 0.55$ & $4.36 \pm 0.60$ & 0.3 \\
GGT (U/L) & $15.3 \pm 1.56$ & $15.2 \pm 1.11$ & 0.9 \\
Alk.P (U/L) & $87.3 \pm 9.78$ & $78.1 \pm 7.64$ & 0.4 \\
PT & $11.2 \pm 0 . .01$ & $11.9 \pm 0.21^{*}$ & 0.008 \\
INR & $1.23 \pm .015$ & $1.13 \pm 0.03^{*}$ & 0.01 \\
\hline
\end{tabular}

${ }^{\star}$ Significant as compared with control (Baseline) at $p$-value $<0.05$. FBS: fasting blood sugar, LFTs: liver function test, Alk.P: alkaline phosphatase, GGT: Gamma-glutamyl transferase, PT: prothrombin and INR: international normalized ratio

Table 2: Effect of omega-3 fatty acid on (mean \pm SE) BMI, BP in the participants for 12 weeks.

\begin{tabular}{cccc}
\hline \multirow{2}{*}{ Parameters } & \multicolumn{3}{c}{ Mean \pm SE } \\
\cline { 2 - 4 } & Baseline & After & p-value \\
\hline BMI & $22.9 \pm 1.48$ & $23.3 \pm 1.39$ & 0.2 \\
Blood pressure & & & \\
SBP (mmHg) & $106.0 \pm 5.41$ & $104.0 \pm 5.42$ & 0.6 \\
DBP (mmHg) & $75.0 \pm 4.01$ & $71.0 \pm 5.85$ & 0.4 \\
MAP & $85.2 \pm 4.21$ & $81.1 \pm 5.45$ & 0.3 \\
\hline
\end{tabular}

Table 3: Effect of omega-3 fatty acid on (mean \pm SE) complete blood count (CBC) in the participants for 12 weeks.

\begin{tabular}{cccc}
\hline \multirow{2}{*}{ Parameters } & \multicolumn{3}{c}{ Mean \pm SE } \\
\cline { 2 - 4 } & Baseline & After & p-value \\
\hline WBC $\left(\mathrm{X} 10^{\wedge} 9 / \mathrm{L}\right)$ & $8.05 \pm 0.94$ & $6.86 \pm 0.55$ & 0.1 \\
$\mathrm{Hb}(\mathrm{g} / \mathrm{dl})$ & $13.7 \pm 0.20$ & $12.9 \pm 0.34^{*}$ & 0.02 \\
$\mathrm{MCV}\left(10^{-15} \mathrm{~L}\right)$ & $84.0 \pm 3.02$ & $82.6 \pm 2.59$ & 0.07 \\
$\mathrm{PLT}\left(\mathrm{X} 10^{\wedge} 9 / \mathrm{L}\right)$ & $270.4 \pm 17.0$ & $276.1 \pm 15.2$ & 0.7 \\
Lymph\% & $38.9 \pm 1.98$ & $33.3 \pm 4.03$ & 0.2 \\
\hline
\end{tabular}

${ }^{*}$ Significant as compared with control (Baseline) at $p$-value $<0.05$ 


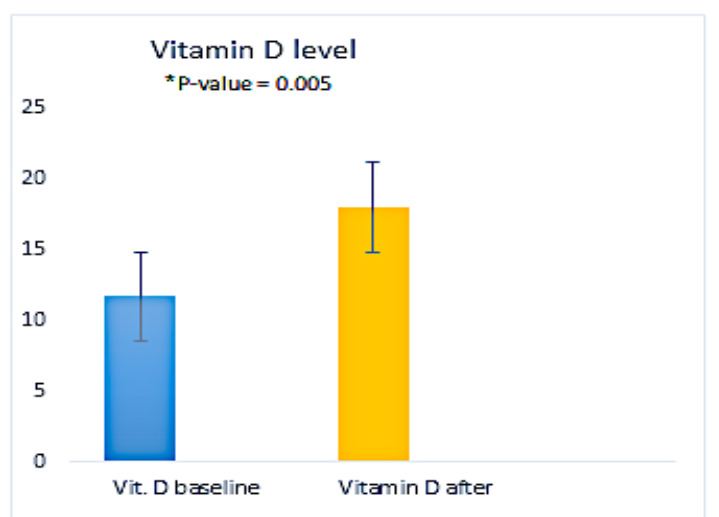

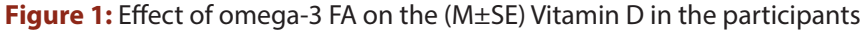
for 12 weeks *Significant as compared with control (Baseline) at $p$-value $<$ 0.05 .

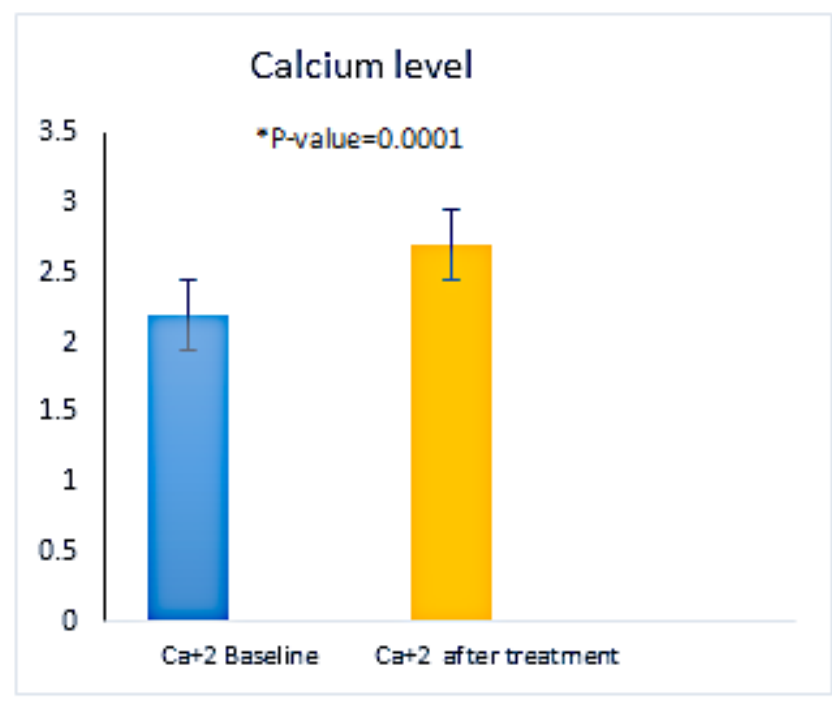

Effect of cmega 3 FA supplements on calcium (mg/dL)

Figure 2: Effect of omega-3 FA on the ( $\mathrm{M} \pm \mathrm{SE})$ calcium in the participants for 12 weeks *Significant as compared with control (Baseline) at $p$-value $<0.05$.

the most category of the population facing these challenges, especially those younger than eighteen years old. ${ }^{20}$ According to the UNICEF report, one childbearing woman and six newborns die every two hours from complications during pregnancy or childbirth. This may refer to the chronic starvation threat and limited mother and childhood health services. ${ }^{21,22}$ One of the maternal complications is vitamins deficiency particularly Vitamin D, which is popular among childbearing age women in developing countries and referred to the concealing clothes wearing that make obstacles for sun radiation penetration and inadequate intake of this vitamin with diet. ${ }^{23,24}$

Vitamin D is a steroid pro-hormone that is involved in the immune system, and the health of bone, muscle, and cardiovascular system. ${ }^{25}$ Moreover, it is deficiently accompanied by many neurological and immunological disorders like depression, ${ }^{26}$ autism, ${ }^{27}$ and metabolic syndrome. ${ }^{28}$ Regarding the omega $3 \mathrm{FA}$ interventional outcomes of this study that continuous intake of it for 12 weeks on bone health and other parameters showed a significant impact on the vitamin D and calcium levels. This effect is accompanied by improvements in lipid profiles particularly cholesterol and LDL-c with no effect on body mass index (BMI) or blood pressure (BP). These findings agree with the

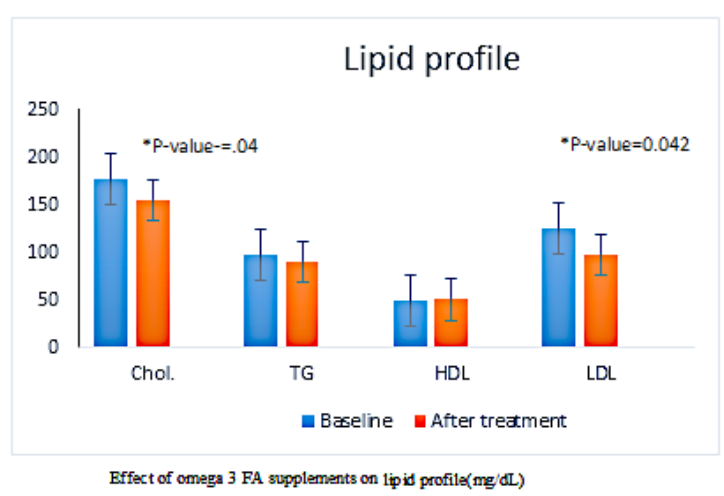

Figure 3: Effect of omega-3 FA on the $(\mathrm{M} \pm \mathrm{SE})$ lipid profile in the participants for 12 weeks. *Significant as compared with control (Baseline) at $p$-value < 0.05 .

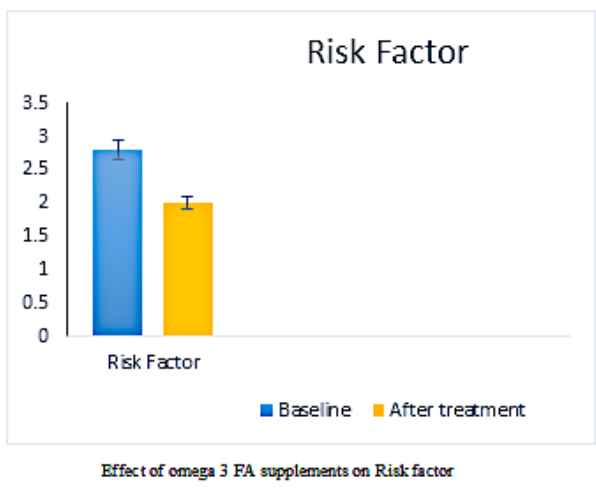

Figure 4: Effect of omega-3 FA on the $(\mathrm{M} \pm \mathrm{SE})$ risk factor in the participants for 12 weeks. Risk factor/means high risk heart disease (the cholesterol ratio by dividing their total cholesterol by their high-density lipoprotein level) *Significant as compared with control (Baseline) at $p$-value $<0.05$.

many studies that referred to the beneficial effects of polyunsaturated fatty acids on the bone explained by different theories. One of these theories, that fish oil increases calcium absorption in the gut, and increasing osteoblast differentiation and activity, reducing osteoclast activity and promoting deposition of mineral in developing bones when feeding rats for 12 weeks. ${ }^{29}$ Additionally, it may increase basal calcium absorption by increasing the activity of Ca-ATPase, which represents the rate-limiting enzyme in calcium uptake. ${ }^{30}$ By increasing calcium absorption, more calcium is available to be incorporated into the bone mineral matrix this correlated to increase bone mineral density (BMD). ${ }^{31}$ Moreover, these polyunsaturated fatty acids may have a role in bone marrow cell development by increasing the cellularity of bone marrow ${ }^{32}$ Additionally; it was found that Omega-3 FA might act as PPAR $\gamma 2$ ligand, which activates adipogenic genes as a transcription factor. Meanwhile, the mesenchymal stem cells (MSCs) in the bone marrow may increase the bone mass or BMD and osteoblastogenesis by differentiating into adipocytes or osteoblasts. ${ }^{33}$ In a clinical trial of 65 elderly women whose diet was low in calcium, supplementation with a properly balanced ratio of polyunsaturated fat plus calcium resulted in decreased bone degradation and increased bone mineral density, with a significant fall in osteocalcin indicative of a decrease in bone turnover. ${ }^{34}$ However, other studies agreed with the outcomes of the present work regarding that omega 3 FA has beneficial effects in reducing TG, and risk of the cardiovascular system through reducing bad lipids including cholesterol, LDL-c and reducing blood clotting cascade ${ }^{35-40}$ as well as modulation of 
the immune system particularly reducing the lymphocyte proliferation. ${ }^{41}$ Contradictory to BMI and blood pressure findings in this study that showed insignificant changes, some studies found that omega 3 FA has significant weight reduction and hypotensive effects especially in obese persons and hypertensive patients. ${ }^{42-44} \mathrm{Du}$ et al. did a review on the antiobesity effect of fish oil, in which 21 studies were included. Through meta-analysis, they concluded no association between fish oil and weight loss, these findings agreed with the present outcomes. ${ }^{45}$

\section{CONCLUSION}

The outcomes of the present study suggest that omega 3 FA, if taken regularly by childbearing women, may improve their maternal outcomes and save their own lives, their babies and prevents adverse pregnancy outcomes, including prematurity, low birth weight, and birth defects, which are the major health concerns. It may have a golden standard role in bone health through strength and activation of Vitamin D thus facilitates calcium absorption and increase bone mineral density. Additionally, it showed cardioprotective and immune modulation effects.

\section{ACKNOWLEDGEMENT}

The authors would like to thank the faculty of Pharmacy and all participants for their valuable support and complete this work.

\section{CONFLICT OF INTEREST}

The authors declare that they have no competing or conflicts of interest.

\section{ABBREVIATIONS}

n-3 FAs: n-3 Fatty acid; RANKL: Receptor activator of nuclear factor kappa-B ligand; SBP: systolic blood pressure; DBP: Diastolic blood pressure; MAP: Mean arterial pressure.

\section{REFERENCES}

1. Ross AC, Manson JE, Abrams SA, Aloia JF, Brannon PM, Clinton SK, et al. The 2011 report on dietary reference intakes for calcium and vitamin D from the Institute of Medicine: What clinicians need to know. J Clin Endocrinol Metab. 2011;96(1):53-8.

2. Knoops KT, DeGroot LC, Kromhout D, Perrin AE, Moreiras-Varela O, Menotti $A$, et al. Mediterranean diet, lifestyle factors and 10-year mortality in elderly European men and women, the HALE project. JAMA. 2004;292(12):1433-9.

3. Kozlowska K, Szczecinska A, Roszkowski W, Brzozowska A, Alfonso C, Fjellstrom CM, et al. Patterns of healthy lifestyle and positive heal attitudes in older europeans. J Nutr Health Ageing. 2008;12(10):728-33.

4. Das UN. Nutrition. Burbank: Los Angeles County, Calif. Estrogen, statins and polyunsaturated fatty acids. 2002;18:178-88.

5. Simopoulos AP. Omega-3 Fatty Acids in Inflammation and Autoimmune Diseases. J Am Coll Nutr. 2002;21(6):495-505. [PubMed: 12480795]

6. Dawczynski C, Schubert R, Hein G, et al. Long-term moderate intervention with n-3 long-chain PUFA-supplemented dairy products: Effects on pathophysiological biomarkers in patients with rheumatoid arthritis. The British Journal of Nutrition. 2009;101(10):1517-26. [PubMed:19245735]

7. Stipanuk MH. Biochemical and Physiological Aspects of Human Nutrition. W.B. Saunders Company; Saunders; 3 editions. 2012.

8. Albertazzi P, Coupland K. Polyunsaturated fatty acids: Is there a role in postmenopausal osteoporosis prevention?. Maturitas. 2002;42(1):13-22. [PubMed: 12020975]

9. Kris-Etherton PM, Taylor DS, Yu-Poth S, et al. Polyunsaturated fatty acids in the food chain in the United States. Am J Clin Nutr. 2000;71(Suppl 1):179S-88S. [PubMed: 10617969]

10. Whelan J, Rust C. Innovative dietary sources of n-3 fatty acids. Annual Review of Nutrition. 2006;26:75-103.

11. Fouda $M$, et al. Vitamin $D$ deficiency in young women of childbearing age: The elephant in the room. Int J Clin Exp Med. 2016;9(2):4615-9.

12. Weiler H, Fitzpatrick-Wong S, Veitch R, Kovacs H, Schellenberg J, McCloy U, et al. Vitamin $\mathrm{D}$ deficiency and whole-body and femur bone mass relative to weight in healthy newborns. CMAJ. 2005;172(6):757-61.

13. Glerup H, Mikkelsen K, Poulsen L, Hass E, Overbeck S, Andersen H, et al. Hypovitaminosis D myopathy without biochemical signs of osteomalacic bone involvement. Calcif Tissue Int. 2000;66(6):419-24.
14. Merewood A, Mehta SD, Chen TC, Bauchner H, Holick MF. Association between vitamin D deficiency and primary cesarean section. J Clin Endocrinol Metab. 2009;94(3):940-5.

15. Laupheimer M. Vitamin D and omega-3 fatty acids in musculoskeletal medicine. International Musculoskeletal Medicine. 2014;36(1):32-5

16. Weiss LA, Barrett-Connor $E$, VonMühlen D. Ratio of $n-6$ to $n-3$ fatty acids and bone mineral density in older adults: The Rancho Bernardo Study. Am J Clin Nutr. 2005;81(4):934-8.

17. Kajarabille $\mathrm{N}$, et al. A New Insight to Bone Turnover: Role of omega-3 Polyunsaturated Fatty Acids. The Scientific World Journal. Article ID 589641.2013;16.

18. Hofbauer LC, Schoppet M. Clinical Implications of the Osteoprotegerin/RANKL/ RANK System for Bone and Vascular Diseases. JAMA. 2004;292(4):490-5. [PubMed: 15280347]

19. World Bank. 2017. Yemen. http://www.worldbank.org/en/country/yemen/ overview (cited on 30/March 2020)

20. Council on Foreign Relations. Yemen in Crisis. 2016. http://www.cfr.org/yemen/ yemen-crisis/p36488 Also see, United Nations Of $\neg$ fice for the Coordination of Humanitarian Affairs (OCHA_: http://www.unocha.org/where-we-work/ emergencies

21. UNICEF. Yemen. 2017. https://www.unicef.org/appeals/yemen.html [cited in 1April 2020]

22. Ministry of Public Health and Population. MOPHP/Yemen, Central Statistical Organization - CSO/Yemen, Pan Arab Program for Family Health - PAPFAM and ICF International: Yemen National Health and Demographic Survey 2013. Rockville, Maryland, USA: MOPHP, CSO, PAPFAM and ICF International. 2015 Available at: http://dhsprogram.com/pubs/pdf/FR296/FR296.pdf

23. Glerup H, Mikkelsen K, Poulsen L, Hass E, Overbeck S, Thomsen J, et al. Commonly recommended daily intake of vitamin $D$ is not sufficient if sunlight exposure is limited. J Int Med. 2000;247(2):260-8.

24. Allali F, EIAichaoui S, Saoud B, Maaroufi H, Abouqal R, Hajjaj-Hassouni N. The impact of clothing style on bone mineral density among postmenopausa women in Morocco: A case-control study. BMC Public Health. 2006;6(1):135

25. Deluca HF. Evolution of our understanding of vitamin D. Nutr Rev. 2008;66(10):s73-87.

26. Berridge M. Vitamin D and Depression: Cellular and Regulatory Mechanisms Pharmacol. 2017;69(2):80-92.

27. Mazahery $\mathrm{H}$, et al. Vitamin $\mathrm{D}$ and Autism Spectrum Disorder: A Literature Review. Nutrients. 2016;8(4):236. doi:10.3390/nu8040236

28. Huszla S, et al. Relationships between Vitamin D3 and Metabolic Syndrome. Int J Environ Res Public Health. 2019;16(2):175. doi:10.3390/ijerph16020175

29. Claassen N, Coetzer H, Papendorp VDH, Kruger MC. Direct determination of saturable and non-saturable calcium uptake in the developing rat duodenum. Lab Anim. 1995;29(4):438-41.

30. Haag M, Magada ON, Claassen N, Bohmer LH, Kruger MC. Omega-3 fatty acids modulate ATPases involved in duodenal $\mathrm{Ca}$ absorption. Prostaglandins Leukot Essent Fat Acids. 2003;68(6):423-9.

31. Lukas R, Gigliotti JC, Smith BJ, Altman S, Tou JC. Consumption of different sources of omega-3 polyunsaturated fatty acids by growing female rats affects long bone mass and microarchitecture. Bone. 2011;49(3):455-62.

32. Lavado-García J, et al. Long-chain omega-3 polyunsaturated fatty acid dietary intake is positively associated with bone mineral density in normal and osteopenic Spanish women. PLoS One. 2018;13(1):e0190539. https://doi. org/10.1371/journal.pone.0190539

33. Atkinson TG, Barker HJ, Meckling-Gill KA. Incorporation of long-chain n-3 fatty acids in tissues and enhanced bone marrow cellularity with docosahexaenoic acid feeding in post-weanling Fischer 344 rats. Lipids. 1997;32(3):293-302.

34. Kruger MC, Coetzer H, DeWinter R, Gericke G, Papendorp VDH. Calcium, gamma-linolenic acid and eicosapentaenoic acid supplementation in senile osteoporosis. Aging. 1998;10(5):385-94.

35. Nilsson A, Radeborg K, Salo I, Björck I. Effects of supplementation with n-3 polyunsaturated fatty acids on cognitive performance and cardiometabolic risk markers in healthy 51 to 72 years old subjects: A randomized controlled crossover study. Nutr J. 2012l;11(1):99.

36. Kim YJ, Kim OY, ChoY, Chung JH, Jung YS, Hwang GS, et al. Plasma phospholipid fatty acid composition in ischemic stroke: Importance of docosahexaenoic acid in the risk for intracranial atherosclerotic stenosis. Atherosclerosis. 2012;225(2):418-24

37. Kander T, et al. Dose-response effects of omega-3 on platelet aggregation: An observational study. Journal of International Medical Research. 2018;46(12):1-9

38. Rosas-Nexticapa M, Caballero-Rodríguez DA, Herrera-Meza S, Acosta-Mesa HG, Santiago-Roque I, Figueroa-Valverde L, et al. Supplementation effect of omega-3 fatty acids in overweight and obese mexican schoolchildren. Interciencia. 2017;42(10):698-704

39. Han SN, Lichtenstein AH, Ausman LM, Meydani SN. Novel soybean oils differing in fatty acid composition alter immune functions of moderately hypercholesterolemic older adults. J Nutr. 2012;142(12):2182-7.

40. Campbell B. Omega-3 Fatty Acids and Obesity. J Food Nutr Disor. 2012;1:2. 
41. Sasikumar E. Impact of Omega 3 Fatty Acids on Blood Pressure. Int J Pure App Biosci. 2014;2(2):106-12

42. Keshavarz SA, et al. Omega-3 supplementation effects on body weight and depression among dieter women with co-morbidity of depression and obesity compared with the placebo: A randomized clinical trial. Clinical Nutrition ESPEN. 2018;25:37-43.

43. Colussi G, et al. Omega-3 Polyunsaturated Fatty Acids in Blood Pressure Control and Essential Hypertension, Chapter from the book Update on Essential
Hypertension. In Tech. 2017. Downloaded from: http://www.intechopen.com/ books/update-on-essentialhypertension

44. Bender N, Portmann M, Heg Z, Hofmann K, Zwahlen M, et al. Fish or n3-PUFA intake and body composition: A systematic review and meta-analysis. Obes Rev. 2014;15(8):657-65.

45. Du S, Jin J, Fang W, Su Q. Does Fish Oil Have an Anti-Obesity Effect in Overweight/Obese Adults? A Meta-Analysis of Randomized Controlled Trials. PLoS One. 2015;10(11):e0142652.

Article History: Submission Date : 07-01-2021; Revised Date : 05-02-2021; Acceptance Date : 26-02-2021

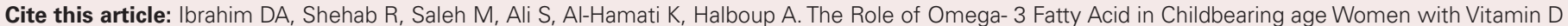
Deficiency in Sana'a City. Int. J. Pharm. Investigation. 2021;11(1):118-22. 